\title{
RANCANG BANGUN MINI TRAINER PRESSURE SENSOR SEBAGAI MEDIA PEMBELAJARAN
}

\author{
Ronald Lorenzo ${ }^{1 *}$, Irma Yulia Basri ${ }^{2}$, Dony Novaliandry ${ }^{3}$, Dedy Irfan ${ }^{4}$ \\ ${ }^{12}$ Program Studi Pendidikan Teknik Otomotif, Universitas Negeri Padang, Indonesia \\ 34Program Studi Pendidikan Teknik Elektronika, Universitas Negeri Padang, Indonesia \\ Jl. Prof. Hamka Kampus UNP Air Tawar Padang \\ *Corresponding Author: ronaldlorenzo36@gmail.com
}

\begin{abstract}
ABSTRAK
Media Pembelajaran merupakan suatu hal yang sangat penting dalam proses belajar mengajar, dengan adanya media pembelajaran mahasiswa bisa memahami pembelajaran dengan lebih baik. Jenis Pressure Sensor (Tekanan) di Jurusan Teknik Otomotif Universitas Negeri Padang belom ada, sehingga mahasiswa masih terkendala dan tidak mampu memahami konsep dan karakteristik sensor. Penelitian ini menggunakan metode penelitian dan pengembangan (Research and Development) yang bertujuan mengetahui unjuk kerja, tingkat kelayakan Trainer Konsep Dasar sebagai media pembelajaran. Pengambilan data dilakukan sebanyak 4 kali pada tiap pengujian, data mentah yang didapat pada saat pengujian diolah dengan beberapa tahap pengujian: Uji Akurasi, Uji Repeatibility, Uji Linearitas, Uji tingkat kelayakan berdasarkan pendapat ahli dan pengguna. Hasil penelitian terhadap unjuk kerja trainer konsep dasar pressure sensor, diketahui uji akurasi menunjukkan rata-rata persentase ketepatan yaitu 99.45\%, uji linearitas data sudah linear, uji repeatability didapat sebesar 0.009, tingkat kelayakan Trainer Konsep Dasar Pressure Sensor dari 4 ahli media dikategori Sangat Layak (91.81\%), tingkat kelayakan Trainer Konsep Dasar Pressure Sensor dari pengguna dikategori Sangat Layak (92.93\%).
\end{abstract}

Kata Kunci: Research and Development, Media Pembelajaran, Trainer Konsep Dasar Pressure Sensor, Unjuk Kerja, Tingkat Kelayakan.

\begin{abstract}
Learning Media is a very important thing in the teaching and learning process, with the learning media students can understand learning better. There are no types of Pressure Sensors in the Department of Automotive Engineering, Padang State University, so students are still constrained and unable to understand the concepts and characteristics of sensors. This study uses research and development methods (Research and Development) which aims to determine the performance, feasibility level of the Basic Concept Trainer as a learning medium. Data retrieval is done 4 times in each test, raw data obtained during testing are processed with several stages of testing: Accuracy Test, Repeability Test, Linearity Test, Test the level of eligibility based on the opinion of experts and users. The results of the trainer performance of the basic concept of the pressure sensor, it is known that the accuracy test shows the average percentage accuracy is $99.45 \%$, the linearity test data is linear, the repeatability test is obtained by 0.009, the feasibility level of the Trainer Basic Concepts of Pressure Sensors from 4 media experts in the category Very Eligible (91.81\%), the feasibility level of the Basic Pressure Sensor Trainer concept from users in the Very Eligible category (92.93\%).
\end{abstract}

Keywords: Research and Development, Learning Media, Trainer Basic Concepts of Pressure Sensors, Performance, Level of Feasibility.

JTIPCAttribution-ShareAlike 4.0 International License

\section{PENDAHULUAN}

Peningkatan kualitas sumber daya manusia dapat dilakukan dengan penambahan ilmu pengetahuan masing-masing individu, terutama dikalangan mahasiswa. Namun masing-masing individu memiliki cara pemahaman yang berbeda- beda dalam proses belajar mengajar. Proses belajar mengajar ada beberapa faktor yang mempengaruhinya yaitu faktor internal (diri mahasiswa itu sendiri) dan faktor eksternal (dari luar diri mahasiswa itu sendiri). Dosen dituntut berinovasi dalam mengembangkan materi untuk 
menciptakan keberhasilan mahasiswa pada mata kuliah yang dibimbingnya. Salah satu inovasi yang dapat dilakukan adalah dengan memaksimalkan penggunaan media pembelajaran atau alat peraga. Media pembelajaran bertujuan agar komunikasi antara mahasiswa dengan dosen berlangsung dengan baik dan materi pembelajaran dapat tersampaikan lebih efektif dan efisien.

Penelitian yang berkaitan dengan dampak positif penggunaan media pembelajaran bagi peserta didik sudah banyak dilakukan. Dari hasil penelitian $70 \%$ responden mengungkapkan lebih mudah memahami materi kimia dengan bantuan media pembelajaran CD Interaktif [1]. Dan setelah menggunakan media pembelajaran trainer kit sensor dikelas XI mata pelajaran Sensor dan Aktuator pada Kompetensi Keahlian Teknik Elektronika Industri di SMK N 2 Pengasih nilai rata-rata siswa dari 57,54 meningkat menjadi 78,68 . Selisih nilai rata-rata siswa mencapai sebesar 21,14 [2].

Media pembelajaran berupa trainer komponen sensor sangat berguna untuk mengetahui fungsi, prinsip kerja dan aplikasi dari dari masing masing komponen sensor. Media pembelajaran ini sangat membantu mahasiswa dalam memahami karakteristik sensor, sehingga relevan antara pembelajaran teori dengan pratikum. Di Universitas Negeri Padang khususnya Jurusan Teknik Otomotif belum ada media pembelajaran yang memadai mata kuliah Sensor dan Tranduser, sehingga tidak seluruh materi bisa diserap oleh mahasiswa, hal ini dapat dilihat target dosen yang mengajar mata kuliah Sensor dan Transduser adalah pada saat ujian awal dosen menargetkan sebanyak 70\% mahasiswa yang rajin masuk dapat menjawab soal ujian dengan benar, tetapi nyatanya hanya 30,64\% dari mahasiswa yang hadir yang dapat menjawab soal ujian Post Test dengan benar. Terdapat pengaruh positif penggunaan bahan ajar berbasis Arduino terhadap prestasi belajar mahasiswa untuk pembelajaran kuliah Mikrokontroler di Politama Surakarta [3]. Hasil penelitian menunjukkan rata-rata nilai posttest kelas eksperimen $(26,49)$ lebih tinggi daripada rata-rata nilai post-test kelas kontrol $(22,03)$. Dampak penggunan media pembelajaran terhadap peningkatan hasil belajar siswa sangat sgnifikan berdasarkan penelitian yag sudah dilakukan, untuk itu peneliti tertarik untuk membuat media pembelajaran yang inovatif.

Media pembelajaran ini didesain untuk memudahkan peserta didik mempelajari jenis sensor. Salah satu media pembelajaran yang peneliti rancang tersebut adalah mini trainer Pressure Sensor. Keunggulan media pembelajaran ini dibandingkan dari media yang beredar dipasaran adalah bentuk yang lebih kecil sehingga efektif untuk dibawa kemana-mana. Mini trainer yang dirancang memperlihatkan konsep dasar dari Pressure Sensor.

\section{KAJIAN TEORI}

\section{A. Media Pembelajaran}

Segala sesuatu yang dapat menimbulkan rangsangan pikiran, perasaan, perhatian dan minat dari peserta didik sedemikian rupa sehingga dapat menghasilkan proses belajar, baik berupa media cetal, audio-visual, alat peraga yang dapat dimanipulasi dan bisa menyampaikan pesan dari materi dapat disebut media [4]. Media pembelajaran adalah perantara yang mengantarkan materi pelajaran oleh pengajar (sumber pesan) kepada siswa (penerima pesan). Pembelajaran dinyatakan efektif apabila dengan menggunakan media pembelajaran, siswa lebih memahami materi pelajaran yang disampaikan oleh pengajar. Manfaat dari penerapan media yaitu dapat memperjelas penyajian pesan dan informasi, mengatasi keterbatasan indera, ruang dan waktu, memberikan kesamaan pengalamaan kepada peserta didik, karean pengetahuan langsung merupakan pengalaman yang diperoleh peserta didik sebagai hasil dari aktivitas sendiri [5]. Media dapat membantu pengajar dalam menyalurkan pesan [6]. Semakin baik media gangguan yang digunakan semakin kecil gangguan dan semakin baik pesan itu diterima oleh siswa. Media dapat digunakan dalam pembelajaran dengan dua cara, yaitu sebagai alat bantu (dependent siswa) dan digunakan sendiri oleh siswa (independent media). Pemakaian media pembelajaran dalam proses belajar mengajar dapat membangkitkan keinginan dan minat yang baru, membangkitkan motivsi dan rangsangan kegiatan belajar, dan bahkan membawa pengaruh-pengaruh psikologis terhadap siswa [7]. Fungsi dan manfaat media pembelajaran berdasarkan beberapa pendapat adalah untuk mempermudah pembelajaran, penyajian, mengatasi keterbatasan ruang, waktu dan daya indera guna untuk membangkitkan motivasi belajar, dan mengatasi sikap pasif pada saat belajar.

\section{B. Trainer Sebagai Media Pembelajaran}

Media apabila dipahami seara garis besar adalah materi, manusia, atau kejadian yang membangun kondisi yang membuat siswa dapat memperoleh pengethuan, keterampilan, atau sikap. Dalam penjelasan ini, buku teks, guru, dan lingkungan sekolah merupakan media [8]. Trainer merupakan suatu set peralatan dilaboratorium yang digunakan sebagai media pendidikan yang merupakan gabungan antara model kerja dan mock up [9]. 
Trainer ditunjukan untuk menunjang pembelajaran siswa dalam menerapkan pengetahuan atau konsep yang diperolehnya pada benda nyata. Model mock up adalah suatu penyederhanaan susunan bagian pokok dari suatu proses system yang lebih rumit.

\section{Arduino Uno}

Arduino adalah sebuah board mikrokontroller yang berbasis ATmega328. Arduino memiliki 14 pin input/output yang mana 6 pin dapat digunakan sebagai output PWM, 6 analog input, crystal osilator $16 \mathrm{MHz}$, koneksi USB, jack power, kepala ICSP, dan tombol reset. Arduino mampu mensupport mikrokontroller dapat dikoneksikan dengan komputer menggunakan kabel USB. Selain itu dalam board arduino sendiri sudah terdapat loader yang berupa USB sebungga memudahkan kita ketika kita memprogram mikrokonroller didalam arduino. Sedangkan pada kebanyakan board mikrokonroller yang lain masih membutuhkan rangkaian loader terpisah untuk memeasukkan program ketika kita memprogram mikrokontroller. Port USB tersebut selain untuk loader ketika memprogram, bisa juga difungsikan sebagai port komunikasi serial.

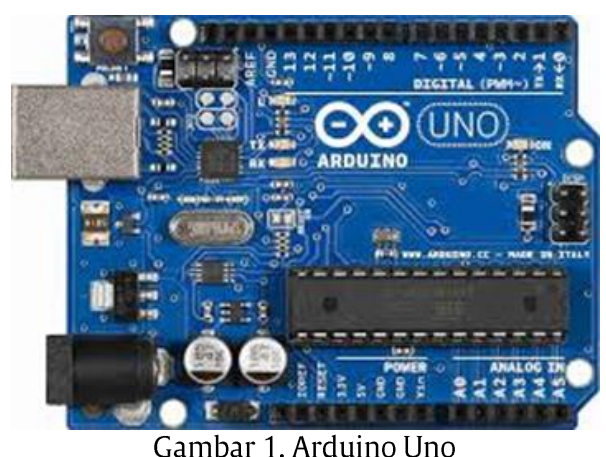

\section{Pressure Sensor (Sensor Tekanan)}

Sensor ini memiliki tranduser yang mengukur ketegangan kawat, dimana mengubah tegangan mekanis menjadi sinyal listrik. Dasar penginderaannya pada perubahan tahanan pengantar (tranduser) yang berubah akibat perubahan panjang dan luas penampangnya. Sensor pengukur tekanan (pressure sensor) bertindak sebagai pembaca nilai tekanan dari materi gas maupun cairan. Piezoelektrik merupakan salah satu komponen elektronik yang banyak digunakan untuk perangkat yang berhubungan dengan bunyi (tone) ataupun sebagai tranduser yang dapat mengubah energy mekanik menjadi energy listrik. Prinsip kerja piezoelektrik sendiri pada pada dasarnya adalah terdiri dari 2 bidang yang berdempet. Yang mana diantara bidang tersebut akan mengasilkan dipole yang terinduksi molekul yang terdiri dari berbagai struktur Kristal tergantung dari bahan pada bidang tersebut.

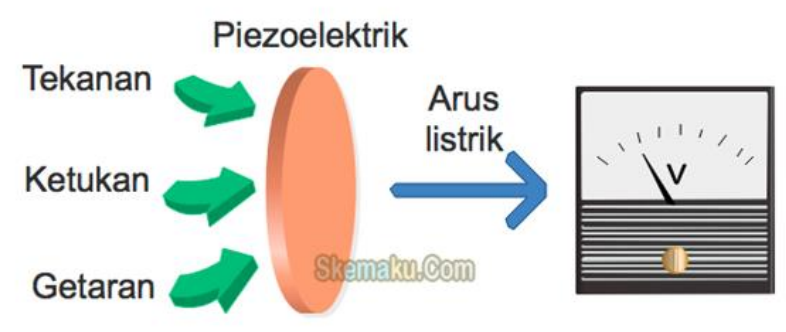

Gambar 2. Piezoelektrik

\section{METODE PENELITIAN}

Jenis metode yang digunakan dalam penelitian ini adalah metode penelitian pengembangan (research and development) metode penelitian pengembangan secara sederhana dapat didefenisikan sebagai metode penelitian yang secara sengaja, sistematis, bertujuan/diarahkan untuk mencari, menemukan, merumuskan, memperbaiki, menghasilkan, menguji keefekitifan produk, model, metode/strategi/cara dan jasa. Prosedur tertentu yang lebih unggul, baru, efektif, efesien, produktif dan bermakna. Menurut [9] penelitian pengembangan adalah metode penelitian yang digunakan untuk mengasilkan produk tertentu dan menguji keefektifan produk tersebut.

Mini Trainer merupakan media pembelajaran berupa replika atau miniatur sebuah perangkat yang disimulasikan dan diterapkan dalam kegiatan pembelajaran teori dan praktik dilaboratorium/perbengkelan yang membantu dan mempermudah mahasiswa memahami dan menguasi materi pembelajaran yang disampaikan. Berikut adalah flowchart yang menggambarkan alur penelitian dari penelitian ini:

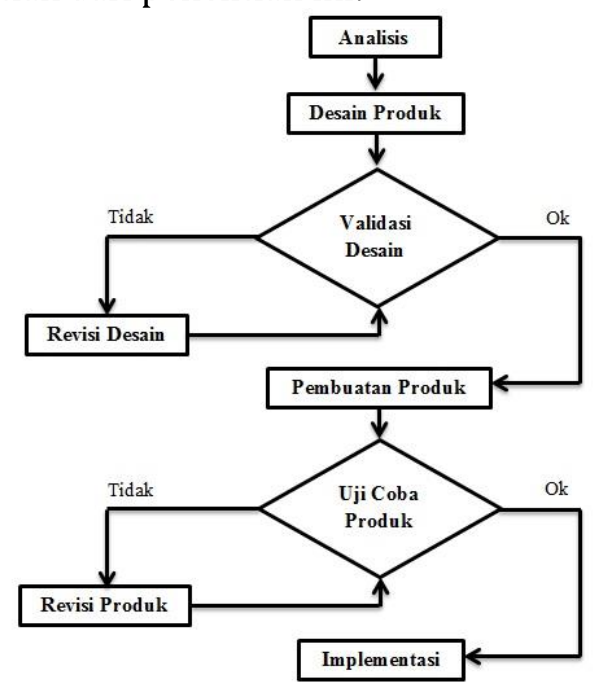

Gambar 3. Flowchart Penelitian 
Adapun penjelasan langkah-langkah penelitian yang digunakan dalam Research and Development berdasarkan flowchart yaitu:

\section{Analisis (Analysis)}

Pada tahap ini dilakukan identifikasi dan kajian tentang media trainer yang selama ini digunakan di Jurusan Teknik Otomotif dalam pembelajaran Sensor dan Tranduser.

\section{Desain (Design)}

Tahap desain (Design) merupakan langkah untuk merencanakan media pembelajaran sensor dan tranduser berupa trainer yang akan dikembangkan sesuai permasalahan yang ditemukan saat tahap analisis.

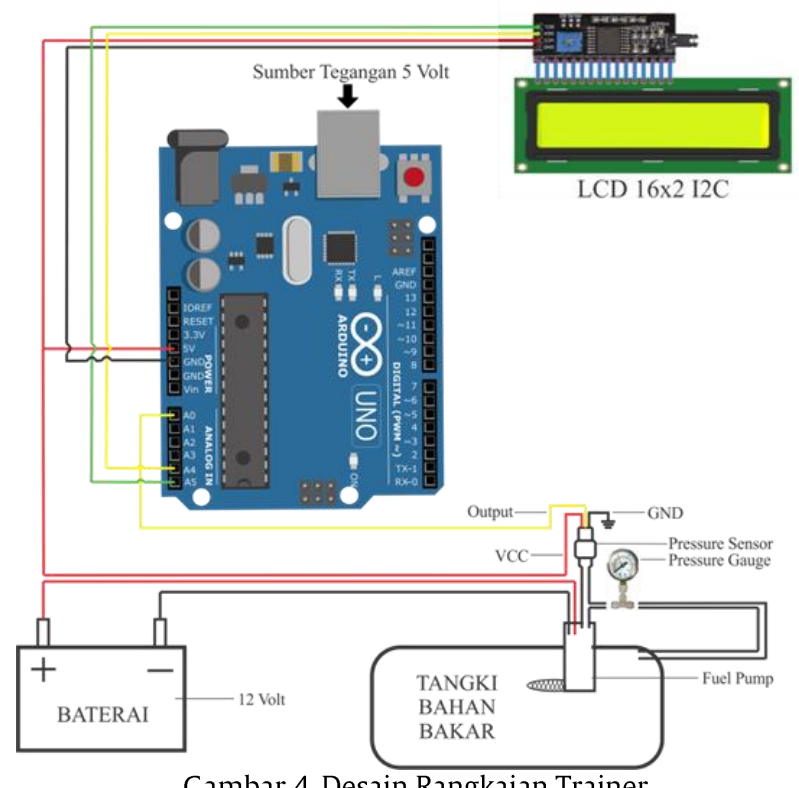

3. Validasi Desain

Berdasarkan masukan dari beberapa ahli media yaitu pada desain harus mengganti pompa bahan bakar menjadi pompa hidrolik, memberi kotak pada arduino agar terlindung dari minyak dan debu, dan menambahkan buzzer pada trainer pressure sensor sebagai tanda peringatan.

\section{Revisi Desain}

Pada tahap ini peneliti memperbaiki kembali desain produk yang telah divalidasi berdasarkan saran perbaikan dari validasi desain, seperti pompa hidrolik, memberi kotak pada arduino agar terlindung dari minyak dan debu, dan menambahkan buzzer pada trainer pressure sensor sebagai tanda peringatan.

\section{Pembuatan Produk}

Berdasarkan desain yang telah dibuat dan telah divalidasi kepada beberapa ahli media maka peneliti akan melakukan pembuatan produk tersebut.

\section{Uji coba Produk}

Tahap uji coba produk akan dilakukan dengan cara melakukan Uji Accuracy, Uji Linearitas, Uji Repeatibility.

\section{Revisi Produk}

Setelah dilakukan uji coba produk terdapat beberapa kesalahan dalam pengujian produk yaitu tekanan yang diberikan oleh pompa bahan bakar terlalu kecil sehingga pompa tersebut harus diganti dengan pompa hidrolik.

\section{Implementasi (Implementation)}

Implementasi Trainer Pressure Sensor sebagai Media Pemebelajaran diterapkan pada mahasiswa Fakultas Teknik Universitas Negeri Padang yang mengikuti mata kuliah sensor dan tranduser. Penerapan dalam pembelajaran bertujuan untuk mengetahui tingkat kelayakan Trainer Pressure Sensor sebagai Media Pemebelajaran pada mata mata kuliah sensor dan tranduser.

Teknik analisis data yang digunakan dibagi menjadi 2 kelompok:

1) Analisis Data valid atau tidak validnya data membandingkan analisis data yang didapat waktu penelitian dengan kajian teoritis. Uji kelayakan yang dilakukan terdiri dari:

a) Uji Accuracy

Ketepatan relatif rata-rata dari sistem pengukuran dapat ditentukan melalui rumus:

$$
\% A=1-(X n-Y n) / Y n \times 100 \%
$$

Keterangan: $Y n=$ nilai pratikum

$$
\mathrm{Xn}=\text { nilai Teoritis }
$$

b) Uji Linearitas

c) Uji Repeatibility

Rumus Repeatibility yang digunakan adalah:

$$
\begin{aligned}
& \mathrm{Rp}=\Delta \mathrm{x} / \mathrm{FS} \times 100 \% \\
& \mathrm{Rp}=\Delta \mathrm{y} / \mathrm{FSO} \times 100 \%
\end{aligned}
$$

2) Analisi Data Uji Kelayakan Menggunakan Angket. Teknik analisis data yang akan dilakukan adalah menggunakan deskriptif kualitatif, yaitu memaparkan produk media hasil rancangan setelah diimplementasikan dalam bentuk produk jadi dan menguji tingkat kelayakan produk. Setelah data-data diperoleh selanjutnya adalah mengubah data kualitatif menjadi kuantitatif dengan menggunakan skala Likert dengan penilaian 4 gradasi yaitu 4, 3, 2, 1 dengan arti Sangat Setuju, Setuju, Tidak Setuju, Sangat Tidak Setuju. Setelah data yang diperoleh, maka selanjutnya adalah melihat bobot pada 
masing-masing tanggapan dan menghitung skor reratanya dengan rumus berikut:

$$
\mathrm{x}^{-}=\left(\sum \mathrm{x}\right) / \mathrm{n}
$$

\section{Keterangan:}

$x^{-}=$Skor/nilai rata-rata

$n=$ Jumlah penilai

$\Sigma x=$ skor/nilai total masing-masing

Rumus perhitungan persentase skor ditulis dengan rumus berikut:

$$
\text { kelayakan } \%=\frac{\sum \text { Hasil Skor }}{\sum \text { Skor Max }} \times 100 \%
$$

Jika nilai persentase rerata telah di dapat maka selanjutnya adalah penunjukan predikat kualitas dari produk yang dibuat berdasarkan skala

\section{HASIL DAN PEMBAHASAN}

1. Produk Konsep Dasar

\section{a. Uji Accuracy}

\begin{tabular}{|c|c|c|c|c|c|}
\hline No & $\begin{array}{c}\text { Menggunakan } \\
\text { Pressure Gauge } \\
\text { (nilai pengukuran) }\end{array}$ & $\begin{array}{l}\text { Rata-rata Menggunakan trainer } \\
\text { konsep dasar (nilai teoritis) }\end{array}$ & $\begin{array}{c}\text { Persentasi } \\
\text { Kesalahan (\%) }\end{array}$ & $\begin{array}{l}\text { Ketepatan } \\
\text { Pengukuran }\end{array}$ & $\begin{array}{c}\text { Persentase Ketepatan } \\
\text { Relatif Rata-rata (\%) }\end{array}$ \\
\hline 1 & 1 & 1.02 & 1.96 & 0.980 & 98.04 \\
\hline 2 & 1.5 & 1.513 & 0.86 & 0.991 & 99.14 \\
\hline 3 & 2 & 2.01 & 0.50 & 0.995 & 99.50 \\
\hline 4 & 2.5 & 2.52 & 0.79 & 0.992 & 99.21 \\
\hline 5 & 3 & 3.02 & 0.66 & 0.993 & 99.34 \\
\hline 6 & 3.5 & 3.52 & 0.57 & 0.994 & 99.43 \\
\hline 7 & 4 & 4.02 & 0.50 & 0.995 & 99.50 \\
\hline 8 & 4.5 & 4.51 & 0.22 & 0.998 & 99.78 \\
\hline 9 & 5 & 5.013 & 0.26 & 0.997 & 99.74 \\
\hline 10 & 5.5 & 5.49 & 0.18 & 0.998 & 99.82 \\
\hline 11 & 6 & 6.01 & 0.17 & 0.998 & 99.83 \\
\hline 12 & 6.5 & 6.58 & 1.22 & 0.988 & 98.78 \\
\hline 13 & 7 & 7.01 & 0.14 & 0.999 & 99.86 \\
\hline 14 & 7.5 & 7.54 & 0.53 & 0.995 & 99.47 \\
\hline 15 & 8 & 8.03 & 0.37 & 0.996 & 99.63 \\
\hline 16 & 8.5 & 8.47 & 0.35 & 0.996 & 99.65 \\
\hline 17 & 9 & 9.09 & 0.99 & 0.990 & 99.01 \\
\hline 18 & 9.5 & 9.56 & 0.63 & 0.994 & 99.37 \\
\hline 19 & 10 & 10.05 & 0.50 & 0.995 & 99.50 \\
\hline 20 & 10.5 & 10.54 & 0.38 & 0.996 & 99.62 \\
\hline 21 & 11 & 11.06 & 0.54 & 0.995 & 99.46 \\
\hline 22 & 11.5 & 11.49 & 0.09 & 0.999 & 99.91 \\
\hline 23 & 12 & 12.01 & 0.08 & 0.999 & 99.92 \\
\hline \multicolumn{5}{|c|}{ Rata - rata ketepatan ( \% ) } & 99.45 \\
\hline
\end{tabular}

Tabel 2. Hasil pengolahan data uji acuuracy pengukuran Rating Scale. Berikut table merupakan Rating scale yang digunakan untuk penafsiran kelayakan produk:

Tabel 1. Kategori Kelayakan Berdasarkan Rating Scale

\begin{tabular}{|c|c|c|}
\hline No. & Skor dalam persen $(\%)$ & Kategori Kelayakan \\
\hline 1 & $0 \%-25 \%$ & Sangat Tidak Layak \\
\hline 2 & $25 \%-50 \%$ & Kurang Layak \\
\hline 3 & $50 \%-75 \%$ & Layak \\
\hline 4 & $75 \%-100 \%$ & Sangat Layak \\
\hline
\end{tabular}

Media pembelajaran dinyatakan layak apabila data hasil penelitian untuk uji kelayakan memiliki ratarata yang memberikan hasil akhir pada kriteria minimal "Layak". Lebih rendah dari kriteria "Layak" atau dalam kriteria "Tidak Layak" maka media pembelajaran tidak dapat digunakan dalam pembelajaran. 
http://tip.ppj.unp.ac.id

Berdasarkan data yang ditampilkan pada tabel 2 Sensor sangat tinggi karena hasil yang ditampilkan menunjukkan bahwa rata-rata persentase ketepatan yaitu 99.45\%. Maka dapat disimpulkan bahwa, pada layar LCD tidak jauh berbeda dengan hasil yang akurasi terhadap alat trainer Konsep Dasar Pressure terbaca pada Pressure Gauge.

\section{b. Uji Linearitas}

Tabel 3. Hasil pengambilan data pengujian produk konsep dasar

\begin{tabular}{|c|c|c|c|c|c|c|c|}
\hline \multirow{2}{*}{ No } & \multirow{2}{*}{$\begin{array}{c}\text { Tekanan } \\
\mathrm{kg} / \mathrm{cm}^{2}(\mathrm{Bar})\end{array}$} & \multicolumn{2}{c|}{ Tegangan Pengujian Pada Trainer Konsep Dasar } & \multicolumn{3}{c|}{ Tegangan Dengan Menggunakan Voltmeter (Volt) } \\
\cline { 3 - 8 } & & 1 & 2 & 3 & 1 & 2 & 3 \\
\hline 1 & 1 & 0.83 & 0.84 & 0.84 & 0.82 & 0.829 & 0.853 \\
\hline 2 & 2 & 1.16 & 1.18 & 1.16 & 1.164 & 1.164 & 1.149 \\
\hline 3 & 3 & 1.50 & 1.49 & 1.51 & 1.479 & 1.477 & 1.481 \\
\hline 4 & 4 & 1.84 & 1.86 & 1.83 & 1.810 & 1.834 & 1.809 \\
\hline 5 & 5 & 2.17 & 2.16 & 2.20 & 2.166 & 2.122 & 2.143 \\
\hline 6 & 6 & 2.50 & 2.50 & 2.58 & 2.534 & 2.534 & 2.515 \\
\hline 7 & 7 & 2.84 & 2.85 & 2.86 & 2.829 & 2.83 & 2.934 \\
\hline 8 & 8 & 3.19 & 3.17 & 3.16 & 3.18 & 3.135 & 3.141 \\
\hline 9 & 9 & 3.54 & 3.54 & 3.53 & 3.56 & 3.56 & 3.362 \\
\hline 10 & 10 & 3.85 & 3.85 & 3.85 & 3.84 & 3.836 & 3.756 \\
\hline 11 & 11 & 4.18 & 4.20 & 4.20 & 4.24 & 4.216 & 4.12 \\
\hline 12 & 12 & 4.51 & 4.51 & 4.48 & 4.49 & 4.49 & 4.50 \\
\hline
\end{tabular}

\section{c. Uji Repeatibility}

Tabel 4. Hasil pengambilan data pengujian Repeatibility produk konsep dasar

\begin{tabular}{|c|c|c|c|c|c|c|c|c|c|c|c|c|}
\hline \multirow[t]{2}{*}{ No } & \multirow{2}{*}{$\begin{array}{c}\text { Tekanan } \\
\mathrm{kg} / \mathrm{cm}^{2} \\
\text { (Bar) }\end{array}$} & \multicolumn{3}{|c|}{$\begin{array}{c}\text { Tegangan Pengujian Pada } \\
\text { Trainer Konsep Dasar } \\
\text { (Volt) }\end{array}$} & \multicolumn{3}{|c|}{$\begin{array}{l}\text { Tegangan Dengan } \\
\text { Menggunakan Voltmeter } \\
\text { (Volt) }\end{array}$} & \multicolumn{3}{|c|}{$\begin{array}{l}\text { Selisih Masing-Masing } \\
\text { Pengujian }\end{array}$} & \multirow[t]{2}{*}{$\begin{array}{l}\text { Rata- } \\
\text { Rata }\end{array}$} & \multirow[t]{2}{*}{$\mathrm{Rp}$} \\
\hline & & 1 & 2 & 3 & 1 & 2 & 3 & 1 & 2 & 3 & & \\
\hline 1 & 1 & 0.83 & 0.84 & 0.85 & 0.82 & 0.82 & 0.84 & 0.01 & 0.02 & 0.01 & 0.013 & 0.003 \\
\hline 2 & 1.5 & 1.01 & 0.99 & 1.00 & 0.99 & 0.99 & 1.00 & 0.02 & 0 & 0 & 0.007 & 0.001 \\
\hline 3 & 2 & 1.16 & 1.18 & 1.16 & 1.16 & 1.16 & 1.14 & 0 & 0.02 & 0.02 & 0.013 & 0.003 \\
\hline 4 & 2.5 & 1.32 & 1.32 & 1.37 & 1.34 & 1.30 & 1.34 & 0.02 & 0.02 & 0.03 & 0.023 & 0.005 \\
\hline 5 & 3 & 1.50 & 1.49 & 1.51 & 1.47 & 1.47 & 1.48 & 0.03 & 0.02 & 0.03 & 0.027 & 0.006 \\
\hline 6 & 3.5 & 1.69 & 1.66 & 1.68 & 1.65 & 1.66 & 1.66 & 0.04 & 0 & 0.02 & 0.02 & 0.004 \\
\hline 7 & 4 & 1.84 & 1.86 & 1.83 & 1.81 & 1.83 & 1.80 & 0.03 & 0.03 & 0.03 & 0.03 & 0.007 \\
\hline 8 & 4.5 & 2.00 & 2.03 & 1.98 & 1.98 & 2.00 & 2.02 & 0.02 & 0.03 & 0.04 & 0.03 & 0.007 \\
\hline 9 & 5 & 2.17 & 2.16 & 2.20 & 2.16 & 2.12 & 2.14 & 0.01 & 0.04 & 0.06 & 0.037 & 0.008 \\
\hline 10 & 5.5 & 2.32 & 2.32 & 2.36 & 2.28 & 2.28 & 2.32 & 0.04 & 0.04 & 0.04 & 0.04 & 0.009 \\
\hline 11 & 6 & 2.50 & 2.50 & 2.58 & 2.53 & 2.53 & 2.51 & 0.03 & 0.03 & 0.07 & 0.043 & 0.010 \\
\hline 12 & 6.5 & 2.69 & 2.69 & 2.69 & 2.66 & 2.66 & 2.60 & 0.03 & 0.03 & 0.09 & 0.05 & 0.011 \\
\hline 13 & 7 & 2.84 & 2.85 & 2.86 & 2.82 & 2.83 & 2.93 & 0.02 & 0.02 & 0.07 & 0.037 & 0.008 \\
\hline 14 & 7.5 & 3.01 & 3.01 & 3.04 & 3.04 & 3.02 & 3.13 & 0.03 & 0.01 & 0.09 & 0.043 & 0.010 \\
\hline 15 & 8 & 3.19 & 3.17 & 3.16 & 3.18 & 3.13 & 3.14 & 0.01 & 0.04 & 0.02 & 0.023 & 0.005 \\
\hline 16 & 8.5 & 3.31 & 3.31 & 3.35 & 3.26 & 3.26 & 3.52 & 0.05 & 0.05 & 0.17 & 0.09 & 0.020 \\
\hline 17 & 9 & 3.54 & 3.54 & 3.53 & 3.56 & 3.56 & 3.36 & 0.02 & 0.02 & 0.17 & 0.07 & 0.016 \\
\hline 18 & 9.5 & 3.70 & 3.66 & 3.71 & 3.74 & 3.72 & 3.82 & 0.04 & 0.06 & 0.11 & 0.07 & 0.016 \\
\hline 19 & 10 & 3.85 & 3.85 & 3.85 & 3.84 & 3.83 & 3.75 & 0.01 & 0.02 & 0.1 & 0.043 & 0.010 \\
\hline 20 & 10.5 & 4.03 & 4.01 & 4.02 & 4.07 & 3.91 & 3.97 & 0.04 & 0.1 & 0.05 & 0.063 & 0.014 \\
\hline 21 & 11 & 4.18 & 4.20 & 4.20 & 4.24 & 4.21 & 4.12 & 0.06 & 0.01 & 0.08 & 0.05 & 0.011 \\
\hline 22 & 11.5 & 4.36 & 4.31 & 4.34 & 4.48 & 4.29 & 4.30 & 0.12 & 0.02 & 0.04 & 0.06 & 0.013 \\
\hline 23 & 12 & 4.51 & 4.51 & 4.48 & 4.49 & 4.49 & 4.50 & 0.02 & 0.02 & 0.02 & 0.02 & 0.004 \\
\hline & & & & & - Rat & peatib & & & & & & 0.009 \\
\hline
\end{tabular}


Berdasarkan tabel 4 hasil pengujian rata-rata Repeatibility dari 3 kali pengujian didapat sebesar 0.009 dan menghasilkan grafik repeatibility seperti gambar di bawah ini. Hasil pengujian pada tabel 3, data yang didapat sudah menunjukkan data linearitas seperti gambar 5. Data linear yaitu setiap kenaikan in put maka tegangan outputnya juga berubah.

\section{d. Uji Tingkat Kelayakan}

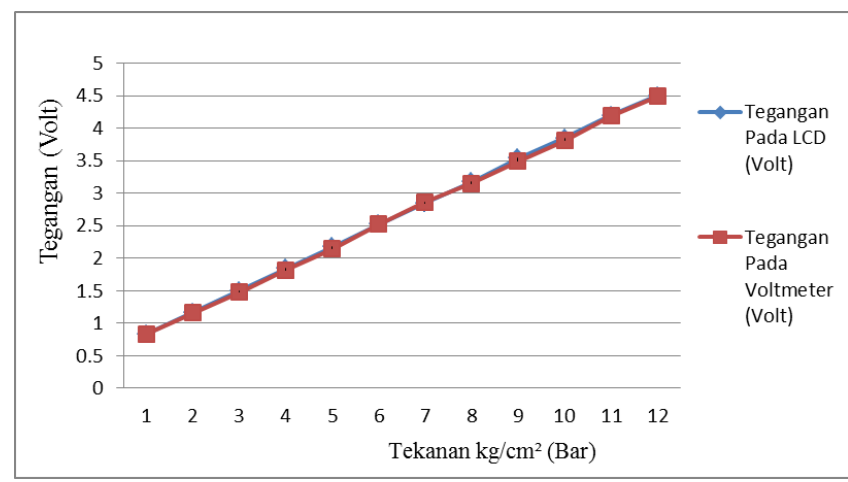

Gambar 5. Grafik Linearitas berdasarkan Output Tegangan

1) Tingkat Kelayakan Oleh Ahli Media

Tabel 5. Hasil Kelayakan Ahli Media Desain Konsep Dasar

\begin{tabular}{|c|c|c|c|c|c|c|c|}
\hline \multirow{2}{*}{ No } & \multirow{2}{*}{ Aspek Kriteria } & \multirow{2}{*}{ No Butir } & \multirow{2}{*}{$\begin{array}{l}\text { Nilai } \\
\text { Max }\end{array}$} & \multicolumn{4}{|c|}{ Ahli Media } \\
\hline & & & & Ahli 1 & Ahli 2 & Ahli 3 & Ahli 4 \\
\hline \multirow{8}{*}{1} & \multirow{8}{*}{ Desain } & 1 & 4 & 4 & 4 & 4 & 4 \\
\hline & & 2 & 4 & 4 & 4 & 4 & 4 \\
\hline & & 3 & 4 & 4 & 4 & 4 & 3 \\
\hline & & 4 & 4 & 4 & 3 & 3 & 4 \\
\hline & & 5 & 4 & 4 & 4 & 3 & 4 \\
\hline & & 6 & 4 & 4 & 4 & 4 & 4 \\
\hline & & 7 & 4 & 3 & 4 & 3 & 4 \\
\hline & & 8 & 4 & 3 & 3 & 3 & 4 \\
\hline \multirow{5}{*}{2} & \multirow{5}{*}{ Pengoperasian } & 9 & 4 & 3 & 3 & 3 & 3 \\
\hline & & 10 & 4 & 3 & 4 & 3 & 4 \\
\hline & & 11 & 4 & 4 & 4 & 4 & 4 \\
\hline & & 12 & 4 & 4 & 4 & 4 & 4 \\
\hline & & 13 & 4 & 3 & 3 & 4 & 4 \\
\hline \multirow{8}{*}{3} & \multirow{8}{*}{ Kemanfaatan } & 14 & 4 & 4 & 4 & 4 & 4 \\
\hline & & 15 & 4 & 3 & 4 & 3 & 4 \\
\hline & & 16 & 4 & 4 & 4 & 3 & 4 \\
\hline & & 17 & 4 & 4 & 4 & 3 & 4 \\
\hline & & 18 & 4 & 4 & 3 & 4 & 4 \\
\hline & & 19 & 4 & 3 & 4 & 3 & 4 \\
\hline & & 20 & 4 & 3 & 3 & 4 & 4 \\
\hline & & 21 & 4 & 4 & 3 & 4 & 4 \\
\hline \multicolumn{3}{|c|}{ Total Skor } & 84 & 76 & 77 & 74 & 82 \\
\hline \multicolumn{3}{|c|}{ Rata - Rata Skor } & 4 & 3.61 & 3.66 & 3.52 & 3.9 \\
\hline \multirow{2}{*}{\multicolumn{3}{|c|}{$\begin{array}{l}\text { Persentasi Rata - rata skor ( \% ) } \\
\text { Prcentaci }\end{array}$}} & 100 & 90.25 & 91.5 & 88 & 97.5 \\
\hline & Persentasi Rata - rata & $\%)$ & 100 & \multicolumn{4}{|c|}{91.81} \\
\hline
\end{tabular}

Berdasarkan tabel 5 data yang diperoleh dari keempat ahli, trainer konsep dasar pressure sensor didapat persentasi rata - rata skor sebesar $91.81 \%$ dan mendapatkan kategori "Sangat Layak".

\section{2) Tingkat Kelayakan Oleh Pengguna}

Uji Kelayakan dilaksanakan pada tanggal 31 Oktober 2019 pada 20 mahasiswa yang telah mengambil dan lulus mata kuliah sensor dan tranduser. Hasil untuk mendapatkan data uji kelayakan dijabarkan pada tabel 6 berikut:
Tabel 6. Hasil Uji Kelayakan Pengguna Desain Konsep Dasar

\begin{tabular}{|c|c|}
\hline Aspek & $\begin{array}{c}\text { Persentasi Tiap Aspek } \\
(\%)\end{array}$ \\
\hline Materi & 96.88 \\
\hline Pengoperasian & 90.97 \\
\hline Kemanfaatan & 90.94 \\
\hline Rata - Rata & 92.93 \\
\hline
\end{tabular}

Berdasarkan hasil yang didapatkan dari ujicoba terbatas, trainer konsep dasar pressure sensor persentasi rata - rata sebesar $92.93 \%$ dikategorikan "Sangat Layak" untuk digunakan dalam proses pembelajaran sensor dan tranduser sebenarnya. 


\section{KESIMPULAN}

Berdasarkan data hasil penelitian dan pembahasan terkait hasil penelitian, maka ditarik beberapa kesimpulan sebagai berikut : Hasil penelitian unjuk kerja Trainer Konsep Dasar Pressure Sensor sebagai media pembelajaran berdasarkan uji akurasi menunjukkan rata-rata persentase ketepatan yaitu $99.45 \%$, uji linearitas data sudah linear, uji repeatability didapat sebesar 0.009, tingkat kelayakan Trainer Konsep Dasar Pressure Sensor dari 4 ahli media dikategori Sangat Layak (91.81\%), tingkat kelayakan Trainer Konsep Dasar Pressure Sensor dari pengguna dikategori Sangat Layak (92.93\%).

\section{SARAN}

Berdasarkan penelitian yang dilakukan, peneliti menyarankan beberapa hal seperti berikut:

1. Penelitian selanjutnya dapat memfokuskan untuk mengamati pengaruh media Trainer Presure Sensor ini terhadap peningkatan hasil belajar mahasiswa.

2. Disarankan untuk penelitian lanjutan, harap menggunakan sensor tekanan dengan rentang kerja yang lebih rendah agar bisa mendeteksi tekanan asli dari pompa bahan bakar.

3. Disarakan untuk penelitian lanjutan, diharapkan menggunakan pompa bahan bakar mobil sebagai sumber tekanan.

\section{DAFTAR PUSTAKA}

[1] Basri, IY., \& Adri, M. (2011). Pemanfaatan Animasi Multimedia pada Mata Kuliah Kimia Teknik untuk Peingkatan Pemahaman Mahasiswa terhadap Konsep Kimia. Jurnal teknologi Informasi dan Pendidikan. Volume 4, No 1 Edisi September 2011. Bagozzi R.P.H. Baumgartener and Yi (1992). State versus action orientation and the Teory of reasoned action. Journal of consumer research.18.505-518.

[2] Wiaksono, AH. 2016. Pengembangan trainer kit sensor sebagai media pembelajaran mata pelajaran sensor dan actuator di smk negeri 2 pengasih.

[3] Haryawan, A. Salechan. 2017. Pengembangan Bahan Ajar Mikrokontroler Berbasis Arduino Sebagai Media Pembelajaran Mata Kuliah Mikrokontroler di Politeknik Pratama Mulia Surakarta. POLITEKNOSAINS, Vol. XVI, No 2, September 2017.
[4] Arsyad, Azhar. 2013. Media Pembelajaran. Jakarta: Raja Grafindo Persada.

[5] Sudjana. Nana, Dasar-Dasar Belajar Mengaja,. Bandung: Alfesindo, 2009.

[6] Widodo, Chomsin S. dan Jasmadi. 2008. Panduan Menyusun Bahan Ajar Berbasis Kompetensi. Jakarta: PT Alex Media Komputindo.

[7] Sadiman, A., \& dkk. 2011. Media Pendidikan: Pengertian, Pengembangan, dan Pemanfaatannya. Jakarta: Rajawali Pers.

[8] Arsyad, Azhar. 2013. Media Pembelajaran. Jakarta: Raja Grafindo Persada.

[9] Fraden, Jacob. 2010. Handbook of Modern Sensors. Physics, Designs, and Applications. New York: acid-free paper.

[10] Sugiyono. 2011. Metode Penelitian Kuantitatif, Kualitatif, Dan R\&D. Bandung: Alfabeta.

[11] Sugiyono. 2012. Metode Penelitian Kuantitatif Kualitatif. Bandung: Alfabeta. 